ISSN 1808-3765

\title{
PLANILHA ELETRÔNICA PARA AUXILIO À TOMADA DE DECISÃO EM MANEJO DE IRRIGAÇÃO
}

\author{
Patricia dos Santos Nascimento ${ }^{1}$, Luís Henrique Bassoi ${ }^{2}$,Vital Pedro da Silva Paz ${ }^{3}$ \\ ${ }^{I}$ Departamento de Engenharia Rural, Faculdade de Ciências Agronômicas, Universidade Estadual Paulista, \\ Rua José Barbosa de Barros, $n^{\circ}$ 1780, e-mail: patyysn@yahoo.com.br. ${ }^{2}$ CPATSA/EMBRAPA, Caixa Postal 23, \\ Petrolina, PE, CEP 56302-97,Fone:(87) 3862171.Email: lhbassoi@cpatsa.embrapa.br; \\ ${ }^{3}$ NEAS/UFRB, Cruz das Almas, BA, CEP 44380-000,Fone:(75) 3621.2798.Email: vitalpaz@ufrb.edu.br.
}

\section{RESUMO}

O manejo de irrigação consiste, basicamente, na adoção de critérios pré-estabelecidos, para a definição do momento e da quantidade de água que deve ser aplicada. Assim, foi desenvolvida uma planilha eletrônica de fácil compreensão, manuseio e interpretação pelo produtor, que utiliza como dados de entrada os atributos físico-hídricos do solo e leituras tensiométricas para determinar a lâmina e o tempo de irrigação, possibilitando que o produtor saiba de maneira rápida o quanto de água aplicar ao solo. A planilha foi testada durante um ciclo de produção de videira irrigada em Petrolina, Pernambuco. As informações da curva de retenção de água no solo e leituras de tensiômetro na profundidade efetiva do sistema radicular da videira foram utilizadas como base para a obtenção do potencial mátrico da água no solo, umidade do solo, água disponível, umidade de reposição, lâmina e tempo de irrigação. O uso da planilha para o manejo de irrigação resultou em menor tempo de aplicação de água, quando comparado ao manejo realizado com base na evapotranspiração da cultura. A planilha pode auxiliar o produtor a realizar ajustes na quantidade de água a ser aplicada quando o manejo de irrigação for baseado apenas na evapotranspiração da cultura.

Palavras-chave: tensiômetro, retenção de água no solo, lâmina de irrigação

\section{NASCIMENTO, P. dos S.; BASSOI, L. H.; PAZ, V. P. da S. SPREADSHEET TO HELP DECISION-MAKING IN IRRIGATION SCHEDULING}

\section{ABSTRACT}

The irrigation scheduling is basically the adoption of pre-established criteria to define the time and the amount of water to be applied through irrigation systems. Hence, the objective of this work was to develop and test a spreadsheet of easy comprehension, handling and interpretation by growers, which uses as inputs the physical-hydric soil attributes and tensiometer readings to the determination of irrigation depth and time. The spreadsheet enables the grower to make reading and to know in a fast way how much water to apply into the soil. The test of the spreadsheet was performed in an irrigated orchard of grapevines in Petrolina, State of Pernambuco, Brazil. Soil water retention curves and tensiometer readings from the effective rooting depth were used as a basis for obtaining the soil water matric potential, soil water content, water availability, soil water content to be replaced, net and gross irrigation depth and irrigation time. The analysis of the use of the irrigation scheduling 
spreadsheet resulted in a shorter time for irrigation in relation to the irrigation scheduling based only on the crop evapotranspiration. The spreadsheet can be helpful to growers adjust irrigation depth when irrigation scheduling is based only on crop evapotranspiration.

Keywords: tensiometer, soil water retention, irrigation depth

\section{INTRODUÇÃO}

Dentre as atividades humanas a agricultura é a que mais consome os recursos hídricos do planeta, sendo a irrigação a responsável por grande parte desse total, chegando a concorrer em algumas regiões de forma direta com a indústria e as cidades pelo uso da água. Nesse processo a irrigação pode ser responsabilizada por problemas de escassez em decorrência do grande volume de água que consome (Queiroz et al., 2008).

A prática da irrigação depende, basicamente, da cultura, do clima e das características do solo. Portanto, o manejo da água em sistemas irrigados tem de levar em conta esses fatores (Oliveira et al., 1999).

Apesar da disponibilidade de vários métodos para a realização do manejo de irrigação, ainda é pequena a adoção dos mesmos por agricultores, sendo a irrigação muitas vezes realizada com base na experiência prática do produtor, sem adoção de qualquer estratégia de uso e manejo racional da água (Costa, 2006).

A ineficiência no manejo adotado por grande parte dos produtores rurais é indicado como um dos fatores que contribui para a escassez dos recursos hídricos. Entre 40 e $60 \%$ da água que é aplicada à cultura são efetivamente usados pela mesma (a maior parcela na forma de transpiração), sendo o restante perdido no sistema, na propriedade e no campo, por meio da evaporação, do escoamento superficial ou da percolação (Albuquerque \& Andrade, 2001).

Faz-se cada vez mais necessária a apresentação de ferramentas que auxiliem o produtor rural na realização do manejo de irrigação. A implantação de um programa de manejo requer conscientização, com visão integrada, tecnologia de ponta e operacionalidade, afim de que se torne possível a otimização do uso dos insumos, aumento da produtividade, rentabilidade e ampliação da área irrigada nos locais com limitação dos recursos hídricos (Bernardo et al., 2006).

No entanto, muitas dessas técnicas ainda são de difícil acesso aos agricultores, os quais necessitam que sejam fornecidas técnicas simples, mas com precisão suficiente para possibilitarem, no campo, a determinação criteriosa do momento e da quantidade de água a ser aplicada (Lopes et al., 2004).

O manejo de irrigação via solo considera a umidade do solo onde o sistema radicular da cultura está se desenvolvendo, sendo o tensiômetro um dos instrumentos mais utilizados e recomendados para o monitoramento da umidade do solo (Bernardo et al., 2006). A utilização da tensiometria com o objetivo de estimar o potencial mátrico da água no solo vem sendo amplamente utilizado por resultar em determinações rápidas, precisas e de baixo custo (Moraes et al., 2006).

As leituras tensiométricas possibilitam melhor entendimento das reais condições hídricas do solo na região do sistema radicular da cultura por monitorar as variações diárias do potencial mátrico do solo e, indiretamente, a variação do armazenamento de água na zona radicular da cultura. O tensiômetro determina a umidade do solo na área a ser irrigada, constituindo assim uma vantagem em relação aos métodos climáticos, os quais muitas vezes recorrem a informações climatológicas de estações meteorológicas situadas em locais muitas 
vezes distantes da área a ser irrigada, acarretando em erros na estimativa da demanda hídrica em escala regional (Lopes et al., 2004).

Tornam-se cada vez mais necessária a criação, difusão e transferência de tecnologias simples e de fácil acesso aos agricultores, de modo que eles possam realizar diretamente no campo a programação efetiva e racional dos recursos hídricos disponíveis sem prejuízos ambientais e econômicos. Segundo Miranda (2005), o uso de recursos da informática como programas (softwares) permitem ao agricultor realizar o manejo da irrigação de forma tecnicamente correta, com maior simplicidade e rapidez.

Para o caso específico do sistema de produção de uvas no Submédio São Francisco, quando o manejo de irrigação é utilizado com base na evapotranspiração da cultura, os técnicos de campo apontam algumas limitações como a falta de conhecimento da umidade do solo antes e após a irrigação, e após a redução da lâmina de irrigação em determinados estádios fenológicos da videira para reduzir o vigor vegetativo da mesma ou para intensificar a coloração vermelha das bagas de algumas variedades. Ao retomar o uso de uma maior lâmina de irrigação após o período desejado de menor disponibilidade de água no solo, persiste para o técnico a dúvida se a camada efetiva do sistema radicular apresenta o aumento esperado da umidade do solo. $\mathrm{O}$ mesmo prevalece quando ocorre uma precipitação, ou seja, até que profundidade do solo a umidade foi elevada, e quando aplicar água novamente e em que quantidade. Ao final do ciclo da videira, quando a necessidade de água pelas plantas é menor, a lâmina de irrigação é reduzida ou interrompida; nesse caso, também falta conhecimento se a redução da umidade do solo foi a desejada.

Este trabalho foi desenvolvido com o objetivo de desenvolver e testar uma planilha eletrônica que utiliza como dados de entrada atributos físico-hídricos do solo e as leituras de tensiômetro para a determinação do potencial mátrico da água no solo, umidade do solo disponível, umidade de reposição, lâmina bruta e tempo de irrigação, possibilitando assim que o produtor faça a leitura e estime rapidamente o quanto de água aplicar ao solo.

\section{MATERIAL E MÉTODOS}

O estudo foi realizado em área de produção comercial de uva, localizada no Perímetro Irrigado Senador Nilo Coelho, Núcleo 5, lote 180 (latitude $9^{\circ} 23^{\prime} \mathrm{S}$, longitude 40 39' O, altitude $394 \mathrm{~m}$ ), em Petrolina - PE. Conforme a classificação de Köppen a região do Submédio São Francisco apresenta clima do tipo BSwh' (Reddy \& Amorim Neto, 1993). O solo da área é classificado como Neossolo Quartzarênico (EMBRAPA, 2006), cuja classe de solo se caracteriza por apresentar grande variabilidade na capacidade de armazenamento de água, drenagem e profundidade da camada impermeável (Silva et al., 2002).

A área de videira escolhida, denominada $\mathrm{K}$, com 3,2 ha, apresentava 40 fileiras de plantas e 41 plantas por fileiras (Figura 1), e era dividida em 4 subáreas de 0,8 ha cada (10 fileiras de planta), correspondentes a área irrigada por cada uma das 4 válvulas de derivação do sistema de irrigação. A videira cv. Crimson Seedless, enxertada sobre o porta-enxerto IAC 313, foi plantada em setembro de 2005, no espaçamento de 5 x $4 \mathrm{~m}$ e irrigada por microaspersão, com 2 difusores por videira, sendo um em cada lado do tronco, no sentido da fileira de plantas. Cada difusor foi instalado a $0,5 \mathrm{~m}$ do tronco e a $1 \mathrm{~m}$ de altura do solo. 


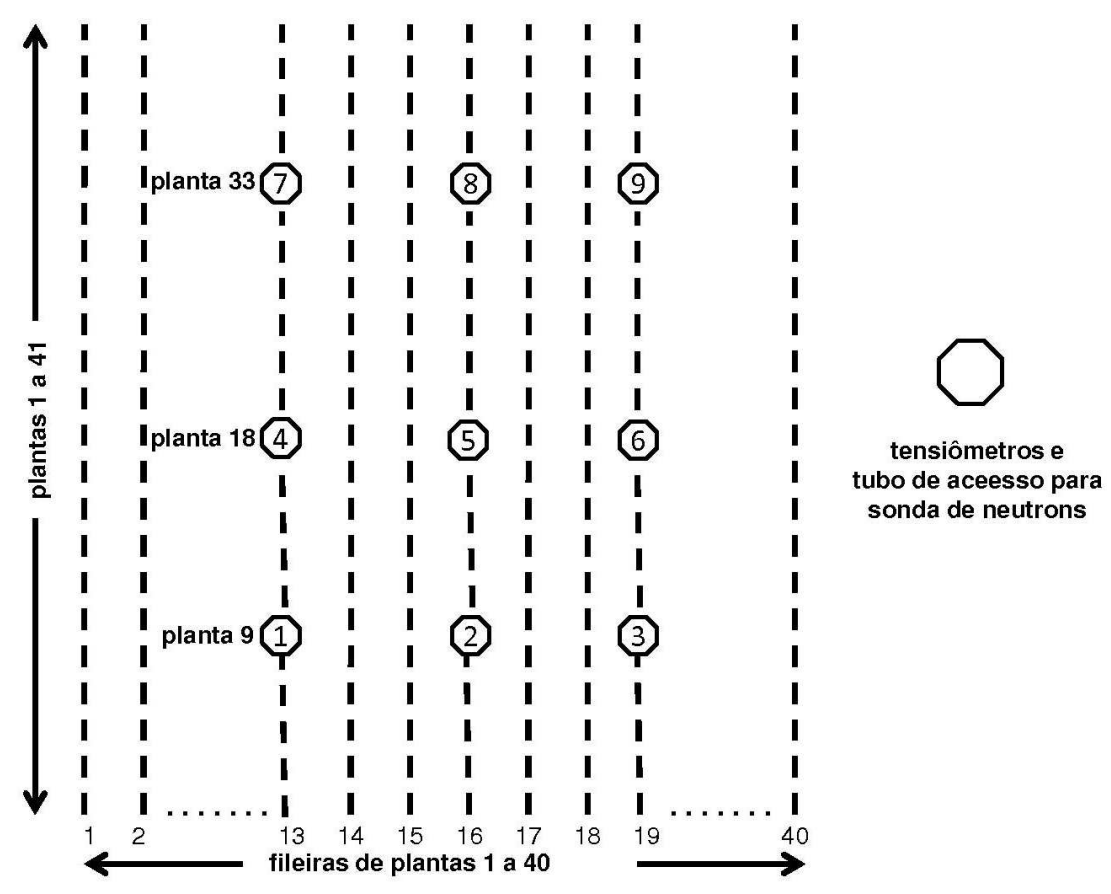

Figura 1. Croqui da área $\mathrm{K}$, com a disposição das baterias de tensiômetros e tubos de acesso para sonda de neutrons nas plantas 9, 18 e 33 das fileiras de plantas 13, 16 e 19.

Foi selecionada para a realização do experimento a segunda subárea (K2) do pomar (fileiras de plantas 11 a 20), sendo escolhidos 3 pontos dessa subárea para a coleta com trado de amostras deformadas de solo para a determinação da curva de retenção da água no solo, nas camadas de 0,0-0,20, 0,20-0,40 e 0,40-0,60 m de profundidade. A determinação dessas profundidades baseou-se na profundidade efetiva de 0,6 $\mathrm{m}$ para o sistema radicular da videira (Bassoi et al., 2002). Os solos coletados nos três pontos foram homogeneizados por camada, formando assim uma amostra composta para cada profundidade para a determinação da curva de retenção de água no solo pelo método da câmara de Richards, às pressões de $0,006,0,01,0$, 033, 0,06, 0,1 e 1,5 MPa.

Nos pontos de coletas de amostras de solo, foram abertas trincheiras até a profundidade de $0,6 \mathrm{~m}$ para a coleta de amostras indeformadas de solo, por meio de anéis cilíndricos de volume conhecido. Após a secagem das amostras indeformadas em estufa a $105^{\circ} \mathrm{C}$, a densidade do solo foi obtida pela relação entre massa de solo seco e volume do solo. Posteriormente, a densidade do solo foi utilizada para obtenção da umidade volumétrica do solo $\left(\mathrm{m}^{3} \mathrm{~m}^{-3}\right)$ a partir da umidade gravimétrica do solo $\left(\mathrm{kg} \mathrm{kg}^{-1}\right)$.

\section{Potencial mátrico de água no solo e umidade do solo}

$\mathrm{Na}$ subárea K2, foram instaladas 9 baterias (Figura 1), com tensiômetros às profundidades de 0,$2 ; 0,4$ e $0,6 \mathrm{~m}$. A determinação do potencial mátrico de água no solo foi realizada duas vezes por semana, por meio de um tensímetro de punção e uma fita métrica para a determinação da altura da lâmina d'água no interior da parte superior (tubo de acrílico) do tensiômetro, que fica acima do nível do solo. Os tensiômetros foram posicionados na área 
umedecida pelo difusor, em um dos lados da videira, a $0,20 \mathrm{~m}$ do tronco, ficando $0,10 \mathrm{~m}$ distanciados entre si em cada bateria. Próximo aos tensiômetros foi instalado em cada bateria um tubo de alumínio para acesso a sonda de neutrons, para o conhecimento da distribuição de umidade do solo às profundidades de 0,$15 ; 0,30 ; 0,45 ; 0,60 ; 0,75 ; 0,90 ; 1,05$ e $1,20 \mathrm{~m}$. As leituras com a sonda de neutrons, previamente calibrada para o solo em questão, foram realizadas nos mesmos dias e horários das leituras de tensiômetro.

\section{Descrição da planilha eletrônica}

A planilha eletrônica foi desenvolvida no software Microsoft Excel sendo constituída por oito partes: 1 - Inserção dos parâmetros da equação de van Genuchten para representação gráfica da curva de retenção de água do solo; 2 - Inserção das leituras de tensímetro; 3 Cálculos do potencial mátrico; 4 - Cálculos da umidade do solo com base na equação da curva de retenção de água; 5 - Cálculos da água disponível no solo; 6 - Cálculos da umidade de reposição; 7 - Cálculos da lâmina bruta de irrigação; 8 - Cálculos do tempo de irrigação.

A planilha desenvolvida permite a inserção de um número variado de baterias, onde cada bateria corresponderá a um conjunto de tensiômetros distribuídos de acordo com a profundidade de interesse do produtor. A tomada de decisão, para melhor orientação ao manejo da irrigação, poderá ser feita com base em todas as baterias ou em grupos de baterias, caso haja o interesse do produtor em verificar a necessidade de irrigação em diferentes partes da área. Essa flexibilidade atende a uma demanda do produtor da área, que vem observando ao longo dos anos uma diferença quanto à drenagem da área em questão. A planilha pode ser reproduzida em outras áreas irrigadas, bastando para isso à inserção dos dados referentes à cultura, solo e sistemas de irrigação específicos de cada área. A planilha deve ser composta por leituras tensiométricas obtidas durante o ciclo da cultura, as quais poderão ser estendidas para o período entre os ciclos da cultura, caso seja de interesse ou necessidade do produtor irrigante saber o quanto de água está presente no perfil do solo durante o período de repouso da cultura.

A evapotranspiração $(\mathrm{ET}, \mathrm{mm})$ foi estimada por uma estação agrometereológica automática Vantage Pro2 ${ }^{\mathrm{TM}}$ (Davis Instruments Corp.), instalada na fazenda, com medidas da temperatura do ar, umidade relativa do ar, velocidade do vento e radiação solar. Os valores de ET foram considerados como de referência, e utilizada para determinação da evapotranspiração da cultura $(\mathrm{ETc}, \mathrm{mm})$, com valores de coeficiente de cultura $(\mathrm{Kc})$ adotados pelo produtor (brotação e crescimento de ramos: 0,5 a 0,6; florescimento: 0,7 ; crescimento de baga: 0,8 a 1,0; maturação à colheita: 0,6 a 0,4).

\section{Descrição dos cálculos realizados pela planilha}

A planilha para auxilio à tomada de decisão quanto ao manejo de irrigação, esquematizada por um heredograma apresentado na Figura 2, utiliza como dados de entrada os parâmetros do solo (umidade de saturação, umidade residual, potencial mátrico e parâmetros empríricos) obtidos a partir da análise de regressão do modelo de van Genuchten (1980) nas profundidades avaliadas, leituras tensiométricas locais e umidade no solo em diferentes percentagens de água disponível. A partir dos dados de entrada é possível a elaboração da planilha, a qual poderá ser aplicada a diferentes sistemas de irrigação e/ou diferentes culturas. 


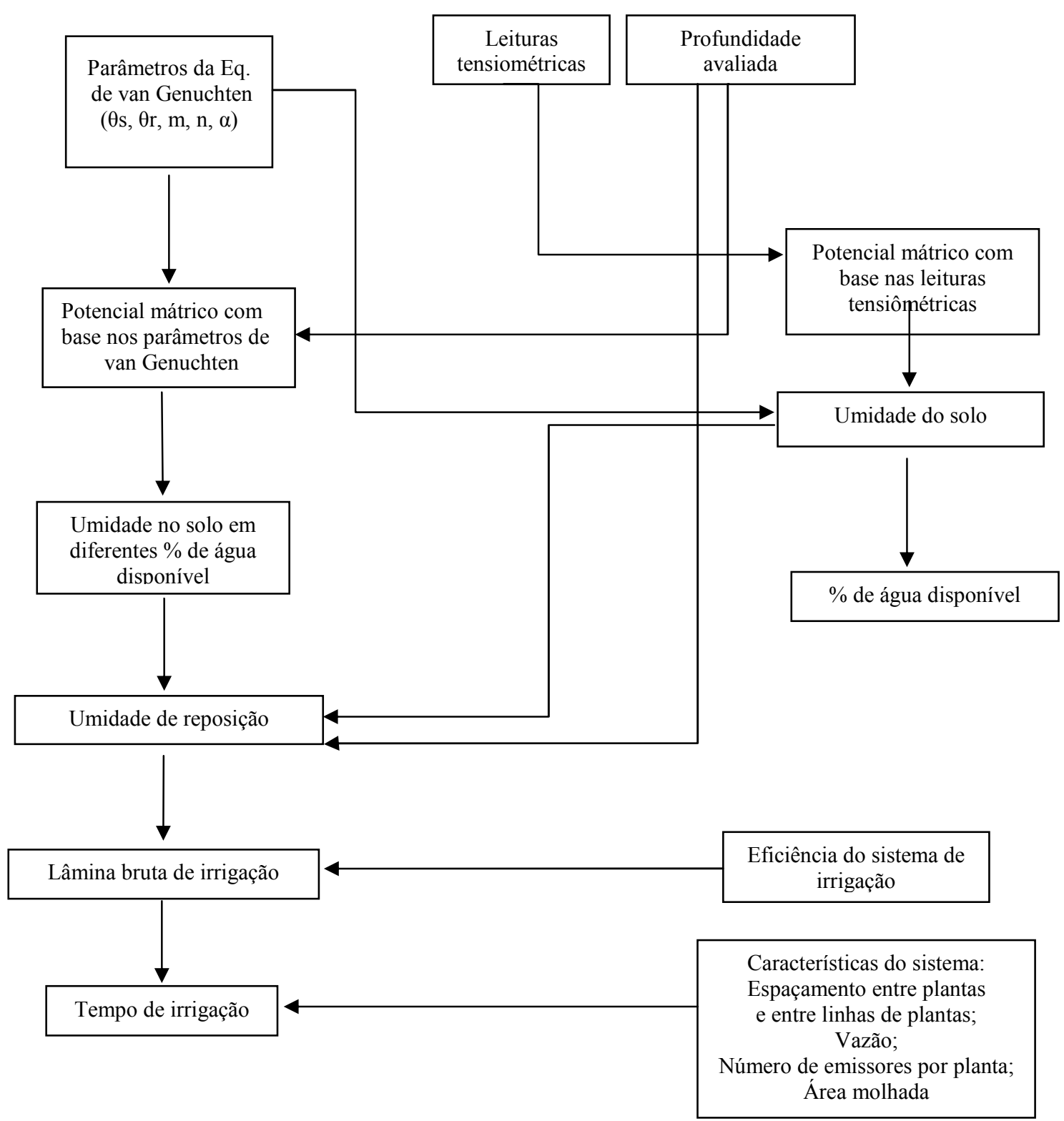

Figura 2. Heredograma representativo da planilha para auxilio a tomada de decisão em manejo de irrigação.

Durante o processo de montagem da planilha são requeridos dados de espaçamento, profundidades do solo a serem monitoradas e do sistema de irrigação (número de difusores por planta, vazão do difusor, eficiência do sistema e fator de redução baseado na área de molhamento). A planilha gera, para as profundidades determinadas, os valores de potencial mátrico, umidade do solo, água disponível, umidade de reposição, lâmina bruta de irrigação e tempo de irrigação. Assim, ao ser inserida a leitura tensiométrica a planilha fornece automaticamente todas as informações citadas anteriormente, pois todas as fórmulas necessárias para a realização dos procedimentos matemáticos já estão inseridas na planilha.

Caso o tensímetro não forneça a leitura na unidade metro de coluna de água (mca) ou centrímetro de coluna de água (cca), a conversão da unidade deverá ser feita para uma delas. Após isso, o cálculo do potencial mátrico é realizado a partir da leitura do tensímetro, 
subtraindo-se as alturas de água no tensiômetro, a altura do tensiômetro em relação ao nivel do solo e a profundidade em que a cápsula porosa está inserida no solo.

A determinação da umidade do solo foi realizada a partir da equação que descreve a curva de retenção de água pelo solo (van Genutchen, 1980) e o potencial mátrico medido na área experimental (Eq. 1).

$$
\theta=\theta_{\mathrm{r}}+\frac{\theta_{\mathrm{s}}-\theta_{\mathrm{r}}}{\left[1+\left|\alpha \psi_{\mathrm{m}}\right|^{\mathrm{n}}\right]^{\mathrm{m}}}
$$

em que,

$\theta \mathrm{r}$ - Umidade volumétrica residual, $\mathrm{m}^{3} \mathrm{~m}^{-3}$

$\theta \mathrm{s}$ - Umidade volumétrica de saturação, $\mathrm{m}^{3} \mathrm{~m}^{-3}$

$\psi_{\mathrm{m}}$ - Potencial mátrico, $\mathrm{MPa}$

$\alpha, \mathrm{m}$ e $\mathrm{n}$ - Parâmetros empíricos da equação

A seqüência da planilha fornece ao produtor a possibilidade de determinação da percentagem de água disponível no solo (AD, \%), a partir da Eq. 2:

$$
\mathrm{AD}=\frac{\left(\theta_{\text {atual }}-\theta_{\mathrm{pmp}}\right)}{\left(\theta_{\mathrm{cc}}-\theta_{\mathrm{pmp}}\right)} \times 100
$$

em que,

$\theta_{\text {atual }}$ - Umidade volumétrica atual do solo, $\mathrm{m}^{3} \mathrm{~m}^{-3}$

$\theta_{\text {pmp }}$ - Umidade volumétrica no ponto de murchamento permanente, $\mathrm{m}^{3} \mathrm{~m}^{-3}$ correspondente a pressão de $1,5 \mathrm{MPa}$

$\theta_{\mathrm{cc}}$ - Umidade volumétrica na capacidade de campo, $\mathrm{m}^{3} \mathrm{~m}^{-3}$ correspondente a pressão de 0,006 $\mathrm{MPa}$

Os valores da umidade do solo na capacidade de campo e no ponto de murchamento permanente são obtidos a partir da curva de retenção determinada para o solo em estudo, inseridos previamente na planilha.

Ao inserir os valores de umidade obtidos da curva de retenção de água no solo a planilha por meio da Eq. 3 já determina a umidade do solo correspondente às diversas percentagens de água disponível (100, 90, 80, 60, 70, etc.):

$$
\theta_{\% \mathrm{AD}}=\theta_{\mathrm{cc}}-\left\lfloor\frac{\left(\theta_{\mathrm{cc}}-\theta_{\mathrm{pmp}}\right) \cdot(100-\mathrm{Pe})}{100}\right\rfloor
$$

em que,

$\theta_{\% \mathrm{AD}}$ - umidade volumétrica correspondente à percentagem de água disponível definida pelo produtor, $\mathrm{m}^{3} \mathrm{~m}^{-3}$

$\theta_{\mathrm{cc}}$ - Umidade volumétrica na capacidade de campo, $\mathrm{m}^{3} \mathrm{~m}^{-3}$

$\theta_{\mathrm{pmp}}$ - Umidade volumétrica no ponto de murcha permanente, $\mathrm{m}^{3} \mathrm{~m}^{-3}$

Pe - Percentual de água disponível estipulado pelo produtor 
Essas percentagens podem ser ajustadas conforme a necessidade da cultura e do sistema de irrigação. Pode-se dizer que a etapa anteriormente descrita integra o conhecimento da necessidade de água de uma cultura de acordo com o seu estádio fenológico, experiência do produtor em relação ao comportamento da cultura (cultivar), clima (época do ano em que se cultiva) e solo (textura, capacidade de retenção de água).

Posteriormente, procede-se a determinação da umidade de reposição. Nessa etapa, o usuário determina a porcentagem de água disponível que deve ser mantida na camada de solo de interesse em função do estádio fenológico da cultura. Ao definir a porcentagem, a planilha por meio da Eq. 4 calcula a umidade de solo correspondente à porcentagem de $\mathrm{AD}$ escolhida $\left(\theta_{\% \mathrm{AD}}\right)$ e o quanto de água deve ser reposta pelo sistema de irrigação. Assim:

$$
\theta_{\text {rep }}=\left(\theta_{\% \mathrm{AD}}-\theta_{\text {atual }}\right)
$$

em que,

$\theta_{\text {rep }}$ - Umidade volumétrica de reposição, $\mathrm{m}^{3} \mathrm{~m}^{-3}$

$\theta_{\% \mathrm{AD}}$ - Umidade volumétrica correspondente à percentagem de água disponível definida pelo produtor $\left(\mathrm{m}^{3} \mathrm{~m}^{-3}\right)$

Caso a $\theta_{\text {atual }}$ seja maior que a $\theta_{\% \mathrm{AD}}$, o valor de $\theta_{\text {rep }}$ será negativo, indicando que não há necessidade de irrigação.

O valor de umidade de reposição multiplicada pela espessura da camada de solo, na qual está sendo realizado o monitoramento estima a lâmina liquida de irrigação para cada camada (Eq. 5):

$$
\mathrm{LL}_{\mathrm{i}}=\theta_{\text {rep }} \times \mathrm{Z}_{\mathrm{i}}
$$

em que,

$\mathrm{LL}_{\mathrm{i}}$ - Lâmina líquida a ser reposta em cada camada i, mm

$Z_{\mathrm{i}}$ - Espessura da camada i, em mm

A correção da lâmina líquida é obtida por meio da divisão da mesma pela eficiência do sistema de irrigação (Eq. 6), gerando assim a lâmina bruta de irrigação por camada de solo considerada e lâmina bruta total, para todas as camadas (Eq. 7), que corresponde à lâmina total que deverá ser aplicada pelo sistema de irrigação:

$$
\begin{aligned}
& \mathrm{LB}_{\mathrm{i}}=\frac{\mathrm{LL}_{\mathrm{i}}}{\mathrm{E}_{\mathrm{i}}} \\
& \mathrm{LB}_{\mathrm{t}}=\sum \mathrm{LB}_{\mathrm{t}}
\end{aligned}
$$

Por fim tem-se a obtenção do tempo de irrigação da cultura que é calculado a partir da Eq. 8: 


$$
\mathrm{T}_{\mathrm{i}}=\frac{\mathrm{LB} \times \mathrm{E}_{1} \times \mathrm{E}_{2} \times \mathrm{P}}{\mathrm{n} \times \mathrm{q}}
$$

em que,

Ti - Tempo de irrigação, $h$

$\mathrm{E}_{1}$ - Espaçamento entre plantas em uma mesma linha, $\mathrm{m}$

$\mathrm{E}_{2}$ - Espaçamento entre linhas de plantas, $\mathrm{m}$

$\mathrm{n}$ - Número de emissores (microaspersor ou gotejador) por planta

q - Vazão do emissor (microaspersor ou gotejador), $\mathrm{L} \mathrm{h}^{-}{ }^{1}$

$\mathrm{P}$ - Porcentagem de área molhada (\%)

Quando a faixa de solo molhada for contínua como no gotejamento ou em microaspersão com sobreposição, como foi o caso desse experimento, a área molhada $\left(\mathrm{A}_{\mathrm{m}}\right)$ poderá ser estimada pela Eq 9:

$$
\mathrm{A}_{\mathrm{m}}=\mathrm{E}_{1} \times \mathrm{D}
$$

$\mathrm{A}_{\mathrm{m}}$ - Área molhada

$E_{1}$ - Espaçamento entre plantas em uma mesma linha, $m$

D- largura da faixa de solo molhado a $20 \mathrm{~cm}$ de profundidade, após a irrigação, $\mathrm{m}$

Com base na $\mathrm{A}_{\mathrm{m}}$ é possível obter a porcentagem de área molhada, Eq. 10:

$$
\mathrm{P}=\frac{\mathrm{A}_{\mathrm{m}}}{\mathrm{E}_{1} \times \mathrm{E}_{2}}
$$

P- Porcentagem de área molhada (\%)

$\mathrm{A}_{\mathrm{m}}$ - Área molhada

$\mathrm{E}_{1}$ - Espaçamento entre plantas em uma mesma linha, $\mathrm{m}$

$\mathrm{E}_{2}$ - Espaçamento entre linhas de plantas, $\mathrm{m}$

\section{RESULTADOS E DISCUSSÃO}

A planilha de auxilio à tomada de decisão quanto ao manejo de irrigação foi avaliada em dois ciclos consecutivos da videira, $1^{\circ}$ e $2^{\circ}$ semestre de 2008 , respectivamente. $\mathrm{O} 1^{\circ}$ ciclo teve início em 14 de janeiro, quando ocorreu a poda de produção da cultura, e final em 14 de maio com a colheita dos frutos, totalizando 121 dias. O ciclo seguinte teve duração de 126 dias, iniciando em 4 de julho (poda de produção), com termino em 14 de novembro. No $1^{\circ}$ ciclo, foi realizado o ajuste da metodologia em campo e aperfeiçoamento da planilha utilizada para o manejo da irrigação, enquanto que o $2^{\circ}$ ciclo caracterizou-se pela utilização efetiva da planilha de auxilio à tomada de decisão em sistemas irrigados com conseqüente validação da mesma.

Para que fosse possível uma comparação em termos de quantidade de água aplicada no ciclo de produção do $2^{\circ}$ semestre de 2008 , o produtor manejou a irrigação nas subáreas K1 e K2 de acordo com a planilha (medidos na subárea K2), enquanto que nas subáreas K3 e K4 o 
manejo foi realizado com base na evapotranspiração da cultura estimada pela evapotranspiração de referência obtida pela estação agrometeorológica automática da fazenda, com uso de coeficientes de cultura para a videira.

O tempo total de irrigação durante o ciclo de produção da videira quando se baseou em parâmetros meteorológicos foi superior $(157 \mathrm{~h})$ ao tempo de irrigação calculado com base na tensiometria $(151 \mathrm{~h})$, conduzindo o produtor a uma redução no tempo total de irrigação de $6 \mathrm{~h}$ ou uma redução de $0,18 \mathrm{~m}^{3}$ no total de água aplicada no ciclo de cultivo, em uma subárea de 0,8 ha. Deve-se ressaltar que o produtor já adotava um critério (ETc) para o manejo de irrigação, e que apesar disso, a adição de um outro critério (umidade do solo) à tomada de decisão ainda possibilitou uma redução do tempo total de aplicação de água. Gondim et al. (2000) e Lopes et al. (2004) também observaram uma redução do tempo de aplicação de água quando o manejo de irrigação baseou-se na tensiometria, em relação ao manejo de irrigação baseado em dados meteorológicos.

A análise da dinâmica da água no perfil do solo de 1,2 $\mathrm{m}$ de profundidade, por meio da determinação da umidade do solo pela técnica de moderação de neutrons, foi realizada nos dois ciclos de produção de uva. No primeiro ciclo, os valores de $\theta$ nas camadas superficiais (Figura 3, superior) foram menores que os das camadas mais profundas (Figura 3, inferior) durante a maior parte do tempo considerado, mas a amplitude de variação foi maior nas camadas superficiais. Isso é decorrente da maior contribuição dessas camadas ao processo de evapotranspiração e ao montante total de precipitação ocorrido durante o primeiro ciclo de cultivo analisado $(199 \mathrm{~mm})$. Nas camadas de solo mais profundas, a partir de $0,75 \mathrm{~m}$, os valores de $\theta$ foram maiores durante a maior parte do período considerado, e sua magnitude de variação foi menor (Figura 3, inferior) devido à menor contribuição ao processo de evapotranspiração e à presença de camadas adensadas no Neossolo Quartazênico, constatado pela presença de mosqueados quando da abertura de trincheiras nessa área.

Em áreas irrigadas do Submédio São Francisco tem sido observado o adensamento em camadas subsuperficiais de solos com elevada porcentagem de areia (EMBRAPA, 2006), decorrentes de processos pedogenéticos (Silva et al., 2002). Tal adensamento constitui-se num fator limitante ao processo de drenagem do solo, e contribuiu para um maior armazenamento de água nas camadas subsuperficiais. 

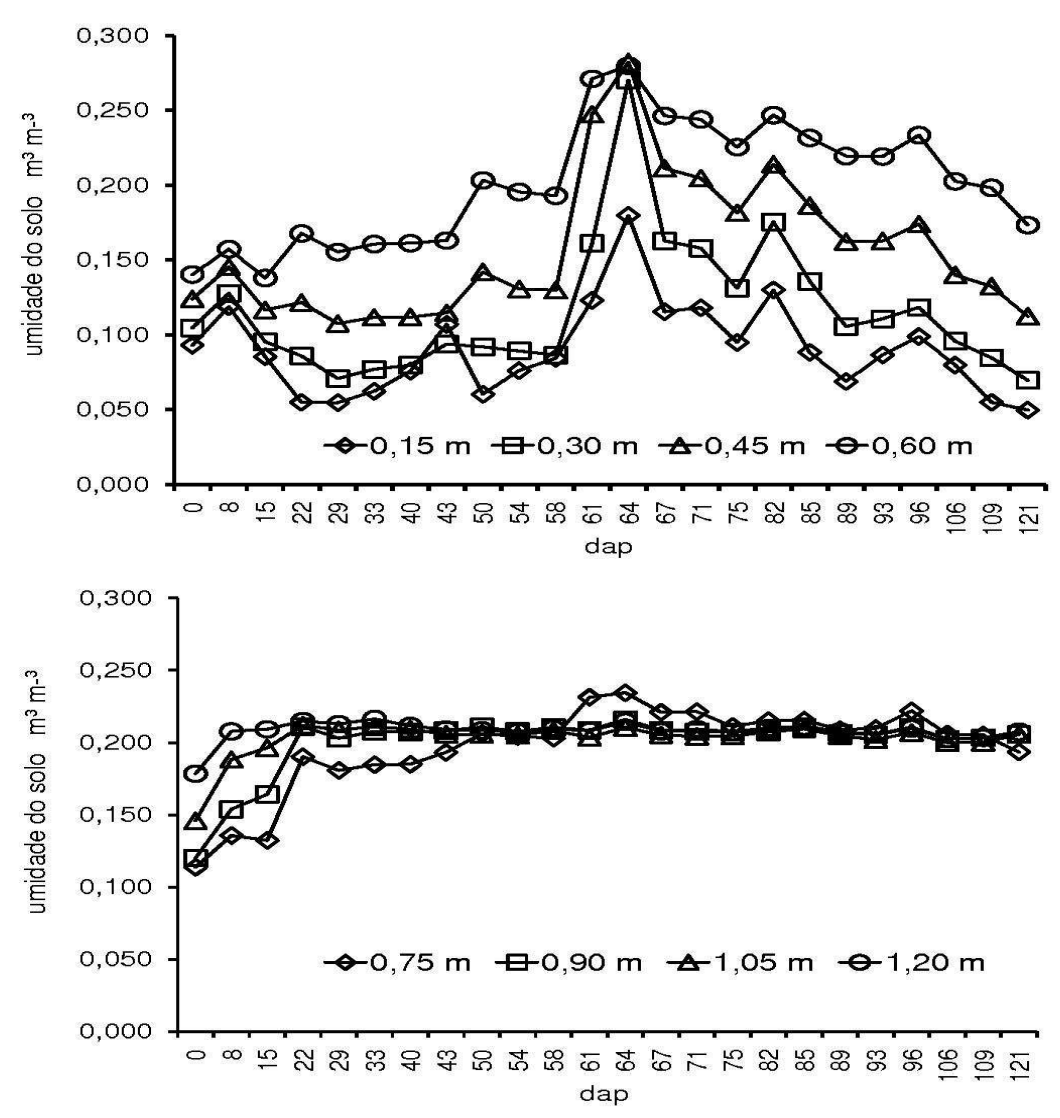

Figura 3. Média das umidades do solo obtidas com sonda de neutrons nas profundidades de 0,$15 ; 0,30 ; 0,45$ e $0,60 \mathrm{~m}$ (superior); 0,$75 ; 0,90 ; 1,05$ e $1,20 \mathrm{~m}$ (inferior), nos dias após a poda (dap), durante o primeiro ciclo de produção de uva.

No segundo ciclo de cultivo da videira os valores de $\theta$ apresentaram-se de modo similar aos observados no primeiro ciclo de cultivo, ou seja, os valores de $\theta$ das camadas superficiais (Figura 4, superior) foram menores que os das camadas mais profundas (Figura 4, inferior), sendo tais diferenças mais visíveis que as do primeiro semestre devido à precipitação de apenas $1 \mathrm{~mm}$ durante o segundo ciclo de cultivo. Mesmo assim, observa-se uma manutenção da umidade do solo nas camadas mais profundas (Figura 4B), com pequena redução dos valores de $\theta$ ao final do ciclo de cultivo, quando a irrigação foi reduzida devido à menor necessidade hídrica da videira. 

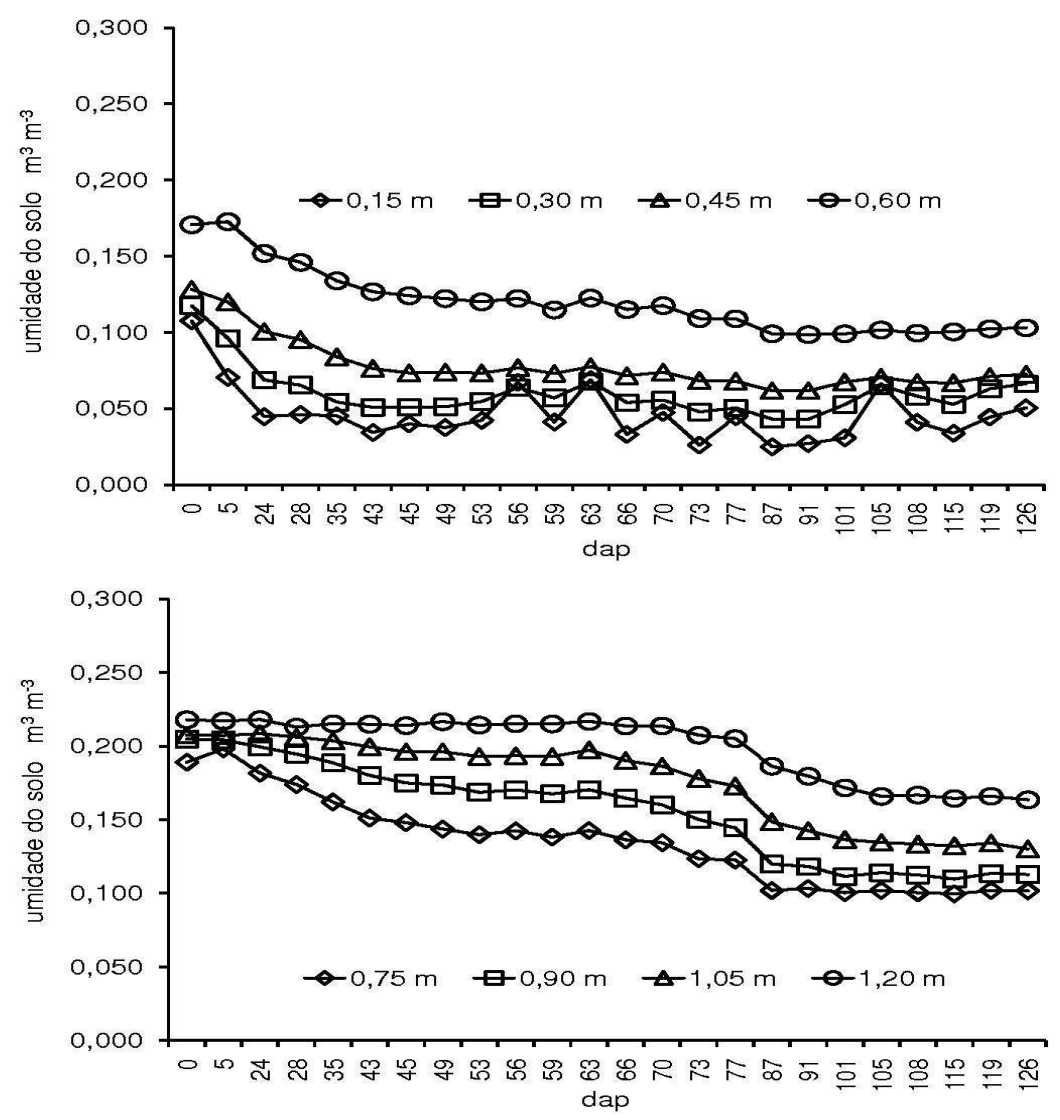

Figura 4. Média das umidades do solo obtidas com sonda de neutrons nas profundidades de 0,$15 ; 0,30 ; 0,45$ e $0,60 \mathrm{~cm}$ (superior); 0,$75 ; 0,90 ; 1,05$ e $1,20 \mathrm{~cm}$ (inferior), nos dias após a poda (dap), durante o segundo ciclo de produção de uva.

A Figura 5 mostra o tempo de irrigação calculado a partir da ETc e o tempo de irrigação calculado pela tensiometria durante todo o ciclo da cultura no segundo ciclo de produção, revelando que os tempos de irrigação observados pelo método tensiométrico estiveram sempre coincidentes ou abaixo dos valores calculados com base na ETc até o 77 dias após poda (DAP). Turco et al. (2009) ao analisarem o custo de energia elétrica em diferentes manejos de irrigação observaram que a tensiometria representou um menor custo de energia, devido ao menor consumo de água observado durante a realização do experimento. No intervalo entre os dias 77 e 95 DAP a irrigação foi interrompida para reduzir a disponibilidade de água às plantas, o que contribui para o aumento da coloração vermelha das bagas de uva cv. Crimson Seedless, de acordo com o critério adotado pelo produtor. 


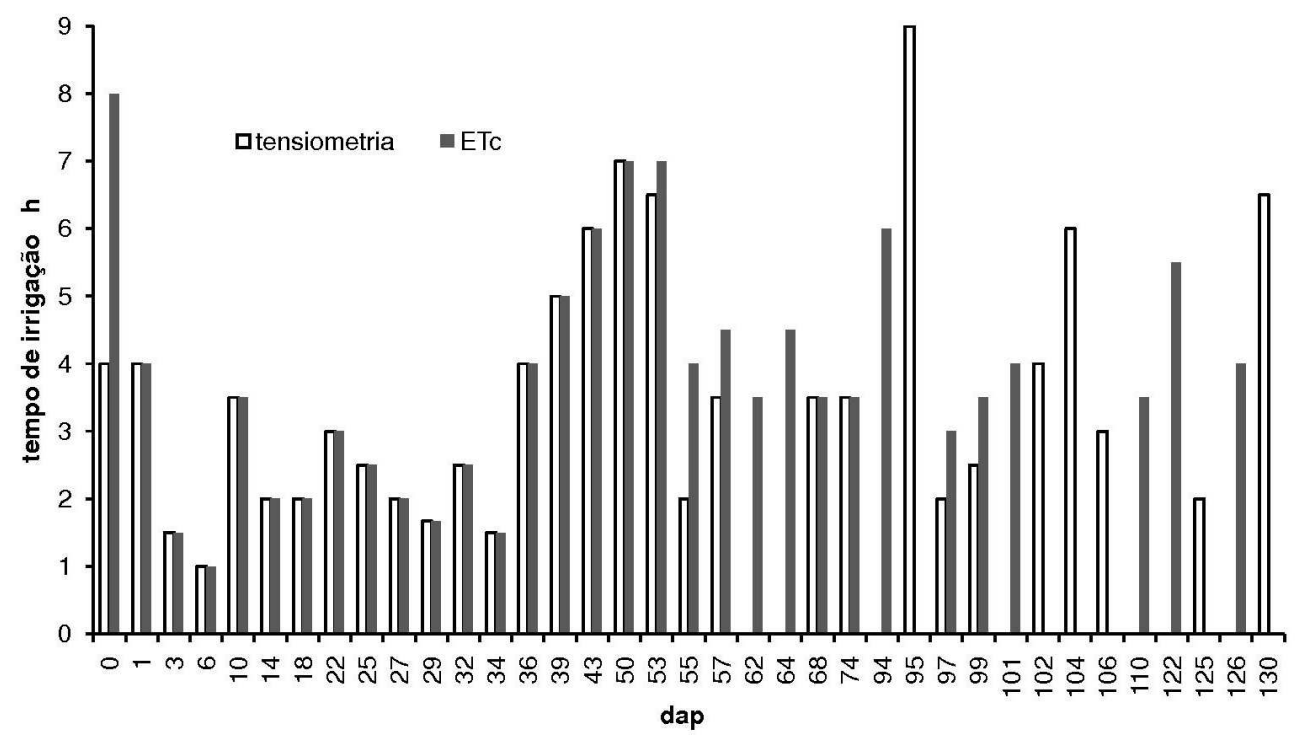

Figura 5. Tempo de irrigação calculado com base nos dados tensiométricos e pela evapotranspiração da cultura (ETc) ao longo do ciclo da cultura.

A irrigação foi retomada a partir de 96 DAP quando o método tensiométrico indicou um maior tempo de irrigação e, por conseguinte uma maior lâmina de irrigação. No terço final do ciclo observou-se uma divergência maior entre os métodos testados quanto ao tempo de irrigação, havendo inclusive um intervalo entre os dias 109 a 125 onde o método tensiométrico indicou interrupção da irrigação enquanto que o método climatológico recomendou o fornecimento hídrico ainda que em menor magnitude.

A tensiometria quando bem conduzida oferece melhor entendimento das reais condições hídricas do solo na região do sistema radicular da cultura (Lopes et al., 2004). A dinâmica da água no solo durante os dois ciclos de cultivo da videira apresentada anteriormente mostra a importância do uso de sensores de umidade do solo para auxiliar o manejo de irrigação, principalmente em regiões onde tal prática é intensa.

Finalmente, é importante frisar que a planilha pode ser uma ferramenta de auxilio à tomada de decisão pelo produtor criterioso quanto ao manejo de irrigação. Podem ser feitos ajustes no manejo de irrigação com base na evapotranspiração da cultura, principalmente quando se deseja saber a umidade do solo antes e após as aplicações de água pelo sistema de irrigação e após a ocorrência de chuvas; quando se deve reiniciar a irrigação após um período de redução ou interrupção da irrigação para o controle do vigor vegetativo da planta e intensificação da cor vermelha da baga; e em quanto está sendo a redução da umidade do solo após a maturação das uvas, no final do ciclo de produção. Tais situações são comuns no sistema de produção de uva no Submédio São Francisco. 


\section{CONCLUSÕES}

A planilha eletrônica desenvolvida e testada é uma ferramenta aplicável ao produtor que deseja um manejo criterioso da irrigação, podendo auxiliá-lo na tomada de decisão quanto a ajustes na lâmina de água calculada com base na evapotranspiração da cultura, e assim reduzir o tempo de irrigação ao longo do ciclo de produção.

\section{REFERÊNCIAS}

ALBUQUERQUE, P. E. P.; ANDRADE, C. L. T. Planilha Eletrônica para a Programação da Irrigação de Culturas Anuais. Sete Lagoas: Embrapa Milho e Sorgo. 2001. 14p. Circular Técnica, 10.

BASSOI, L. H.; GRANGEIRO, L. C.; SILVA, J. A. M.; SILVA, E. E. G. Root distribution of irrigated grapevine rootstocks in a coarse texture soil of the São Francisco Valley, Brazil.

Revista Brasileira de Fruticultura, v.24, p.35-38, 2002.

BERNARDO, S.; SOARES, A. A.; MANTOVANI, E. C. Manual de irrigação. 8ed. Viçosa: UFV, 2006. 625p.

COSTA, M. B. da. Avaliação da irrigação por pivô central na cultura do café (Coffea canefhora $L$.) e na cultura do mamoeiro (Carica papaya L.) no município de Pinheiros ES. Piracicaba: ESALQ, 2006. 89 f. Tese Doutorado.

EMBRAPA - Empresa Brasileira de Pesquisa Agropecuária. Centro Nacional e Pesquisa em Solos. Sistema Brasileiro de Classificação de Solos. Brasilia: Embrapa SPI; Embrapa Solos, 2006. 306p.

GONDIM, R. S.; AGUIAR, J. V. DE; COSTA, R. N. T. Estratégias de manejo de água em caupi irrigado. Revista Brasileira de Engenharia Agrícola e Ambiental, Campina Grande, v.4, p.14-18, 2000.

LOPES, A. S.; PAVANI, L. C.; CORÁ, J. E.; ZANINI J. R.; MIRANDA, H. A. Manejo da irrigação (tensiometria e balanço hídrico climatológico) para a cultura do feijoeiro em sistemas de cultivo direto e convencional. Engenharia Agrícola, Jaboticabal, v.24, p.89-100, 2004.

MIRANDA, F. R. de. Irrigacaju: Planilha eletrônica para o manejo da irrigação na produção integrada de caju. Fortaleza: Embrapa Agroindústria Tropical. 2005. 8p. Circular Técnica, 23.

MORAES, N. B. de; MEDEIROS, J. F. de; LEVIEN, S. L. A.; OLIVEIRA, A. M. de S. Avaliação de cápsulas de cerâmica e instrumentos de medida de tensão usados em tensiômetros. Revista Brasileira de Engenharia Agrícola e Ambiental, Campina Grande v.10, p.58-63, 2006. 
OLIVEIRA, F. A. de; CAMPOS, T. G. da S.; OLIVEIRA, B. C. Efeito de tensões de água no solo sobre o rendimento do algodoeiro herbáceo. Pesquisa Agropecuária Brasileira, Brasília, v.34, p.1905-1911, 1999.

QUEIROZ, T. M. de; BOTREL, T. A.; FRIZZONE, J. A. Desenvolvimento de software e hardware para irrigação de precisão usando pivô central. Engenharia Agrícola, Jaboticabal, v.28, p.44-54, 2008.

REDDY, S. J.; AMORIM NETO, M.S. Dados de precipitação, evapotranspiração potencial, radiação solar global de alguns locais e classificação climática do Nordeste do Brasil. Petrolina: Embrapa/CPATSA. 1993. 280 p.

SILVA, M. S. L. da; KLAMT, E.; CAVALCANTE, A. C.; KROTH, P. L. Adensamento subsuperficial em solos do semi-árido: processos geológicos e/ou pedogenéticos. Revista Brasileira de Engenharia Agrícola e Ambiental. Campina Grande, PB, v.6, p.314-320, 2002.

TURCO, J. E. P.; RIZZATTI, G. dos S.; PAVANI, L. C. Custo de energia elétrica em cultura do feijoeiro irrigado por pivô central, afetado pelo manejo da irrigação e sistemas de cultivo. Engenharia Agrícola, v.29, p.311-320, 2009.

VAN GENUCHTEN, M. T. A closed form equation for predicting the hydraulic conductivity of unsaturated soils. Soil Science Society of America Journal, v.44, p.892-898, 1980. 